\title{
Teoría de la mediatización: una perspectiva semio-antropológica*
}

\author{
Eliseo VERÓN ${ }^{1}$
}

\section{MEDIATIZACIÓN Y SU INTERVALO DE TIEMPO}

El (relativamente) viejo problema de las relaciones entre medios y las sociedades en las que la expansión de las redes de comunicación se lleva a cabo, ha recibido un gran impulso en aproximadamente las últimas dos décadas y en consecuencia ha adoptado una nueva forma. En los últimos años, un número de perspectivas teóricas y proyectos de investigación alrededor de este problema han sido vagamente identificados como pertenecientes al estudio de la "mediatización". Como la "mediatización" es, lingüísticamente hablando, un sustantivo que nombra a un proceso, las entidades consideradas sujetas a ese proceso son, en la mayoría de los casos, las sociedades en tanto tales o subsistemas particulares de estas. A su vez, fundamentalmente, el período histórico bajo escrutinio es el de la modernidad, y a veces el de la modernidad tardía, como por ejemplo en el uso del concepto por parte de Hjarvard: "la mediatización no es ningún proceso universal que caracterice a todas las sociedades. Es principalmente un desarrollo que se ha acelerado particularmente en los últimos años del siglo veinte sobre todo en las sociedades occidentales modernas y altamente industrializadas, como Europa, Estados Unidos, Japón, Australia y otras similares" (Hjarvard 2008: 113)2.

Adoptaré aquí el punto de vista casi opuesto, a favor de una perspectiva histórica de la mediatización a largo plazo. ¿Cuán extensa debería ser esta perspectiva? Como veremos, mientras más extensa mejor, y esto justifica la calificación de esta perspectiva como "antropológica". La mediatización ciertamente no es un proceso uni-

\footnotetext{
* Publicado en Mediatization of Communication, 2014, vol. 21, p. 163.

1 Traducido por Celeste Wagner, Departamento de Ciencias Sociales, Universidad de San Andrés (mwagner@udesa.edu.ar).

2 Con respecto a esto, revisar el clásico de Thompson (1995).
} 
versal que caracterice a todas las sociedades humanas, del pasado y del presente, pero sí es, sin embargo, un resultado operacional de una dimensión fundamental de nuestra especie biológica, que es la capacidad de semiosis. Esta capacidad ha sido progresivamente activada, por diferentes razones, en una variedad de contextos históricos y, por lo tanto, ha tomado muchas formas. Pero algunas de sus consecuencias estuvieron presentes desde el primer comienzo en nuestra historia evolutiva, y afectaron a la organización social de las sociedades occidentales mucho tiempo antes de la modernidad.

Necesitamos algunas herramientas conceptuales para proseguir. Llamaré fenómeno mediático a los productos de la capacidad semiótica de nuestra especie. Un fenómeno mediático es la exteriorización de procesos mentales bajo la forma de un dispositivo material dado. Los fenómenos mediáticos son, en efecto, una característica universal de todas las sociedades humanas. La primera etapa de la semiosis humana ha sido, por consiguiente, la producción sistémica de las herramientas de piedra, que comenzó hace alrededor de dos millones y medio de años. Las industrias de piedra, desde un punto de vista semiótico, son sistemas de significación secundarios (comparados con un sistema de significación primario como el lenguaje) en términos de la clásica distinción propuesta mucho tiempo atrás por Claude LéviStrauss (1958). La percepción, por parte de los miembros de una comunidad primitiva, de una punta de flecha de piedra - un elemento material en el entorno psicológico inmediato de una comunidad - implicaba la activación de un proceso semiótico, propiamente dicho: hacia atrás, hacia la secuencia del comportamiento técnico que llevó a su fabricación; hacia adelante, hacia su uso como un instrumento para obtener alimento. Ambos movimientos mentales son - siguiendo las dimensiones de la tríada de Peirce - secuencias indiciales (segundidades) contenidas en la configuración icónica (primeridad) de la punta de flecha de piedra. Si en la comunidad el perceptor es, por ejemplo, un cazador, un movimiento mental relativo a las reglas del correcto uso del instrumento (una terceridad) probablemente también se activaría $^{3}$. La fuerte discusión en curso acerca de los orígenes del lenguaje debería tener en cuenta el funcionamiento subyacente de los procesos semióticos implicados en las exteriorizaciones visuales icónicas y en las secuencias indiciales de operaciones técnicas de producción de instrumentos, ambos procesos que preceden a la aparición del lenguaje y que son cualitativamente diferentes de él (Verón 2013, cap. 13).

El punto central aquí es que el fenómeno mediático de exteriorización de procesos mentales tiene una triple consecuencia. Nuevamente en términos peircianos, la primeridad consiste en la autonomía de emisores y receptores de los signos materializados, como un resultado de la exteriorización; la secundidad es la subsecuente persistencia en el tiempo de los signos materializados: las alteraciones de las escalas de espacio y tiempo se vuelven inevitables, y narrativamente justificadas; su terceridad es el cuerpo de las normas sociales que definen las formas de acceso a los signos ya autónomos y persistentes. En otras palabras: triple creación de diferencias.

\footnotetext{
${ }^{3}$ Como es bien conocido, Peirce discute su modelo de las tres categorías de maneras muy diferentes a lo largo de sus escritos. Una particularmente interesante y clara presentación, probablemente escrita en 1894, ha sido incluida en la selección recientemente publicada por el Peirce Edition Project (Peirce 1894, volume 2: 4-10).
} 
Las condiciones están dadas, entonces, para que la historia de la mediatización comience. Algunos de sus momentos han sido sujetos a examen histórico: la aparición de la escritura, el pasaje del rollo al códice, esto es, la aparición del libro; la "revolución inadvertida" de la imprenta, en la expresión de Elizabeth Eisenstein (1983); la proliferación de los panfletos y la subsecuente aparición de los periódicos; a comienzos del siglo diecinueve, nuevos dispositivos técnicos permitieron la aparición de nuevos fenómenos mediáticos que permitieron, por primera vez, la producción indicial de encuadre y secuenciación temporales de imágenes y sonido, dispositivos que culminaron, un siglo después, con la invención de la televisión (para todos estos momentos cruciales ver Verón 2013 y la bibliografía allí incluida).

En este contexto, la mediatización es solamente el nombre para la larga secuencia histórica de fenómenos mediáticos institucionalizados en las sociedades humanas y sus múltiples consecuencias. La ventaja conceptual de una perspectiva de largo plazo es recordarnos que lo que sucede en las sociedades de la modernidad tardía comenzó de hecho hace mucho tiempo. La etapa inicial de cada momento crucial de la mediatización puede ser fechada, porque consiste en un dispositivo técnico-comunicacional que ha aparecido y se ha estabilizado en comunidades humanas identificables, que quiere decir que ha sido, de alguna u otra forma, "adoptado". No hay ningún determinismo tecnológico implicado aquí: cada vez, la apropiación de un dispositivo técnico por una comunidad puede adoptar muy diferentes formas; la configuración de usos que finalmente se institucionaliza en un lugar y tiempo determinados alrededor de un dispositivo comunicacional (configuración que puede ser apropiadamente llamada medio), solo necesita de la explicación histórica.

\section{MEDIATIZACIÓN COMO UN PROCESO NO LINEAL}

En primer lugar, el surgimiento de un medio (o muchos medios), operando a través de un nuevo dispositivo técnico-comunicacional, típicamente produce "efectos radiales", en todas direcciones, afectando de diferentes formas y con diferentes intensidades a todos los niveles funcionales de la sociedad.

En segundo lugar, estos "efectos" radiales y transversales de los fenómenos mediáticos son resultado de su naturaleza sistémica, lo que implica una enorme red de relaciones de retroalimentación: los fenómenos mediáticos son claramente procesos no lineales, típiacmente alejados del equilibrio (ver Prigogine y Stengers 1984, Kauffman 2000). En el marco de una teoría de los discursos sociales, este carácter no lineal de la comunicación puede estar representado por la distinción entre condiciones y gramáticas de producción, por un lado, y condiciones y gramáticas de reconocimiento, por el otro: en el nivel social, la circulación discursiva del sentido está estructuralmente quebrada 5 .

${ }^{4}$ La comunicación no mediática también es un proceso no lineal. La mediatización puede ser descripta como la macro generalización de esta condición de circulación humana de signos, que consiste en la diferencia estructural entre producción y reconocimiento. El desarrollo conceptual de estos puntos excede los límites de este artículo; ver Verón 1987, 2013. 
En tercer lugar, (1) y (2) explican la consencuencia más impresionante de la mediatización: la aceleración del tiempo histórico. Cada caso de aceleración debería, por supuesto, ser evaluado de acuerdo con el ritmo que caracteriza al período histórico del que estemos hablando.

\subsection{EL PRIMER FENÓMENO MEDIÁTICO PRIMARIO: LA ESCRITURA}

Tomemos un ejemplo - históricamente el más importante- del cambio multidimensional introducido por un fenómeno mediático: la emergencia de la escritura y la alfabetización. Jack Goody es la mejor autoridad en este caso; sus análisis de las consecuencias de la cultura escrita pueden sintetizarse en los siguientes puntos:

\subsubsection{Adopción de una posición metalingüistica y el comienzo de la reflexión sobre el lenguaje}

Las palabras se convirtieron en objetos duraderos antes que en evanescentes señales audibles. Esta transformación significa que las comunicaciones a través del espacio y el tiempo se encuentran alteradas de modos significativos. Al mismo tiempo, la materialización del acto discursivo en la escritura permite que sea inspeccionado, manipulado y reordenado en una variedad de formas. (...) Los morfemas pueden ser removidos del cuerpo de la oración, el flujo del discurso oral, y apartados como unidades aisladas capaces no simplemente de ser ordenadas en una oración, sino de ser ordenadas por fuera de este marco, donde aparecen en un contexto abstracto y muy diferente (Goody 1977: 76-78).

\subsubsection{Estimulación y persistencia de una actitud crítica}

La proposición específica es que la escritura, y más específicamente la alfabetización, hicieron posible escudriñar el discurso de un modo distinto al darle a la comunicación oral una forma semi-permanente; este escutrinio favoreció un aumento en el alcance de la actividad crítica, y por ende de la racionaidad, el escepticismo y la lógica (...). Aumentó las potencialidades del pensamiento crítico porque la escritura desplegó el discurso ante los ojos de una manera diferente; al mismo tiempo aumentó la potencialidad del conocimiento acumulativo, especialmente del conocimiento de tipo abstracto (Goody 1977: 37).

\subsubsection{Reorganización cultural de los espacios mentales concernientes al tiempo histórico}

En el nivel de la enunciación, la persistencia y la autonomía generadas por el fenómeno mediático de la escritura transformaron a los textos, como un resultado de la acumulación, en testimonios materiales del paso del tiempo, medido por los diferentes sistemas de calendario que comenzaron a tomar forma. En el nivel de las proposiciones, el rol de los proto-géneros discursivos debería tenerse en cuenta, parti- 
cularmente la lista (Goody 1977: 74-111). Producir listas es un proceso cognitivo fuertemente disociado de la comunicación oral (Goody 1977: 80-82). Las listas jugaron un rol fundamental en el control político y administrativo de las nuevas sociedades en las que se propagó la alfabetización.

\subsubsection{Transformación de los intercambios orales}

Como un resultado de estos nuevos espacios mentales asociados con la escritura, la comunicación oral en sí misma también se transformó. En relación con lo que Goody llama la "descontextualización" producida por la escritura, dice:

No quiero dar a entender que estos procesos no pueden ocurrir en el discurso oral. Por ejemplo, podemos de pronto interrumpir el flujo del discurso y repetir algo que acabamos de decir (...). También uno puede corregir una parte del discurso o refrasear una oración incluso después de que haya sido dicha para evitar separar un infinitivo o terminar con una preposición. Pero la misma declaración de estas Posibilidades hace evidente cómo la escritura puede facilitar el proceso o la reorganización, así como afectar más permanentemente la esfera de la comunicación verbal. Porque hay dos situaciones orales: aquella que prevalece en la ausencia de la escritura y aquella que prevalece en su presencia. Estas dos situaciones son ciertamente diferentes, dado que la escritura no es que simplemente se agrega a la oralidad como otra dimensión: altera la naturaleza de la comunicación verbal (Goody 1977: 78).

\subsubsection{Nuevas formas de control, burocratización y dominación}

La invención de la escritura produjo, desde sus comienzos, un instrumento ideal de control social, que hizo posible la expansión y estabilización de los crecientes grandes imperios, facilitando su necesaria burocratización. ¿Pero cuál es el tópico de la mayor parte del material escrito? Incluso en tiempos asirios, no es el principal el relato o la narrativa tradicional, ya sea en la forma de creaciones literarias o en el registro de mitos y cuentos populares, sino mas bien son los documentos administrativos y económicos, encontrados en los templos y palacios alrededor de Babilonia y cubriendo una extensión geográfica y cronológica más amplia que los registros más académicos (Goody 1977: 79).

En lo que a esto respecta, podemos hipotetizar un largo proceso histórico con retroalimentaciones sucesivas. La cultura escrita facilita las dimensiones organizacionales y burocráticas de la sociedad, legitimando al mismo tiempo las relaciones jerárquicas. La complejidad creciente y el tamaño de las culturas escritas aumentan la importancia de la autonomía y persistencia de los discursos, destinados a la administración de las creencias, asegurando una estabilización colectiva de éstas, lo que las situaciones orales cara a cara tienen más y más dificultad para lograr. Esto conduce finalmente a la noción de las "sagradas escrituras", donde los elementos escritos asumen el rol central de la estructuración de los afectos y creencias relativos a la narrativa fundacional de la sociedad. 


\subsubsection{Transformación de las condiciones sociales de la individuación}

En las comunidades sin escritura, los contenidos culturales están principalmente alojados en la memoria individual. Los elementos significativos en las múltiples situaciones de la vida cotidiana son preservados y activados por los contactos personales entre miembros; el resto es olvidado. En una cultura escrita, los contenidos culturales aumentan constantemente, y el miembro individual de la sociedad se convierte en una especie de palimpsesto compuesto de muchas capas de creencias y actitudes que pertenecen a los diferentes períodos históricos (Goody y Watt 1963).

En resumen: la cultura escrita transformó la relación con la tradición y las formas de acumulación y transmisión de valores culturales; modificó profundamente la representación social del tiempo y de la historia; reconfiguró la conversación y los intercambios interpersonales; hizo posible la operación de nuevos mecanismos políticos y económicos, lo que condujo a la emergencia de los grandes imperios e hizo posibles nuevos modos de construir la identidad personal. Este conjunto de cambios sociales es lo que llamo "efectos radiales", que caracterizan la naturaleza no lineal de cada uno de los momentos centrales de la mediatización.

\subsection{LA ACELERACIÓN DEL TIEMPO HISTÓRICO}

Con el fin de tener una narrativa mínima, mencionemos por lo menos tres puntos aquí.

a) Cuando las culturas del Paleolítico Superior aparecieron, los productos de las industrias de piedra pasaron de veinte tipos básicos de herramientas a doscientas variedades y —Richard Leakey (1994) juiciosamente remarcó- la escala del cambio pasó, en años, de cientos de miles a un ritmo de miles.

b) La impresión apareció a mediados del siglo XV; hay, pienso, un fuerte consenso entre los historiadores de que, durante los dos siglos que siguieron a la invención de Gutenberg, Europa cambió económica, política, social y culturalmente, más que en los anteriores mil o quinientos años (ver Eisenstein 1979, 1983, 2011).

c) En los últimos diez años, Internet ha alterado las condiciones de acceso al conocimiento científico más de lo que estas condiciones cambiaron desde el surgimiento de las instituciones científicas modernas durante el siglo XVII.

Muchos otros ejemplos de esta aceleración del tiempo histórico como resultado del surgimiento de fenómenos mediáticos pueden ser identificados, por supuesto, en un sentido mucho más preciso, referidos prácticamente a cualquier sector particular de actividades sociales y/o culturales. La transformación del mundo musical, por ejemplo (en todos sus aspectos: composición, performatividad y audiencias), durante las dos o tres décadas posteriores a la invención de la grabación, a fines de siglo XIX, es incomparablemente más profunda que lo que sucedió en el mundo musical 
durante los anteriores tres o cuatro siglos (Philip 2004). La invención de la fotografía, y sus consecuencias en la frontera tradicional entre espacio público y vida cotidiana privada, es otro de los casos que vale la pena mencionar (Verón 1994).

\section{ALTERACIONES DE ESCALA}

Ya hemos subrayado el hecho de que los fenómenos mediáticos producen autonomía de emisores y receptores y persistencia de los discursos a través del tiempo. La primera consecuencia de la autonomía y la persistencia es la descontextualización del sentido, lo que ha marcado desde sus inicios la historia de la localización, salvaguardia, lectura e interpretación de textos -primero de los rollos y luego de los códices. La descontextualización abre la puerta para las múltiples rupturas de espacio y tiempo producidas de una manera específica por cada dispositivo, a través de toda la historia de la mediatización. La invención de la imprenta democratizó, por decirlo así, la descontextualización y la hizo disponible para todos. Desde este punto de vista, la historia de la mediatización puede ser contada como la interminable lucha entre grupos sociales confrontados tratando de estabilizar sentidos, lucha que se convierte, a lo largo de la historia de nuestra especie, crecientemente más compleja y crecientemente más condenada al fracaso.

En las ciencias sociales, la comunicación interpersonal o "cara a cara" ha sido muy frecuentemente conceptualizada como un intercambio lineal, "directo", opuesto a los procesos de comunicación mediados por un dispositivo técnico. Desde mi punto de vista, la comunicación humana es enteramente no lineal, a todos sus niveles de funcionamiento, porque es un sistema auto-organizante muy alejado del equilibrio. La especificidad de la comunicación "cara a cara" no es su supuesta linealidad, sino la ausencia de fenómenos mediáticos. En consecuencia, en intercambios interpersonales las posiciones de la enunciación (enunciador, discurso y destinatario) están localizadas en el mismo punto homogéneo de espacio-tiempo. En este contexto, ¿puede la descontextualización tener lugar en un nivel no mediático de la comunicación? Sí, porque el lenguaje oral, en una comunidad humana antes de la aparición de la escritura, hace posibles alteraciones imaginarias de espacio y tiempo, incluso si son fugaces, frágiles y no tienen ninguna persistencia material: por ejemplo, un adulto explicando a un grupo de niños, en una sociedad ágrafa, cómo comportarse durante la ceremonia ritual que se llevará a cabo al día siguiente. Podemos considerar este tipo de situación como implicando una distorsión imaginaria de tiempo y espacio. Los fenómenos mediáticos materializan las distorsiones y las convierten en rupturas de espacio-tiempo. La metodología recientemente desarrollada de análisis de cognigramas de la conducta prehistórica relativa a las herramientas formaliza la distancia entre problema y solución: una determinada conducta con una herramienta está orientada a la producción material de un objeto, digamos una herramienta de tallado, con unas cualidades materiales que serán significativas en otros lugares y/o momentos (Haidle 2009). Con los fenómenos mediáticos, la diferenciación entre sistemas sociales y sistemas psíquicos -en el sentido de Luhmann (1984), Verón, (2013) — puede tener comienzo, y sin un posible retorno; 
con la escritura, el Homo sapiens definitivamente abandonó un cierto tipo de locación estructural de espacio-tiempo.

Realicemos una síntesis filogenética. ¿Los fenómenos mediáticos son una precondición de los sistemas psíquicos de los homo sapiens? La respuesta es no. De modo inverso: ¿los sistemas psíquicos de los homo sapiens son una precondición de los fenómenos mediáticos? La respuesta es sí. ¿Los sistemas psíquicos son una precondición de los sistemas sociales? La respuesta es sí, no en un sentido lineal, pero sí a través de la aparición de los fenómenos mediáticos. ¿Los fenómenos mediáticos son una preconduición de los complejos sistemas sociales? La respuesta es sí. Los fenómenos mediáticos, y por ende la mediatización, son así de fundamentales.

\section{LA NEGOCIACIÓN DE NUNCA ACABAR ENTRE SISTEMAS SOCIA- LES Y SISTEMAS AUTOPOIÉTICOS SOCIO-INDIVIDUALES}

Hoy en día, me parece que el punto central tanto para la investigación como para la construcción de teoría es trabajar en las relaciones particulares entre fenómenos mediáticos y no mediáticos, relaciones a lo largo de toda la historia de la mediatización caracterizadas por tensiones importantes y contradicciones. En otras palabras, tenemos que prestar especial atención a las dimensiones no mediatizadas de los procesos sociales. Porque si todo es mediatización, el concepto en sí pierde mayor interés.

Este problema ha sido discutido por Niklas Luhmann bajo el concepto de "interpenetración" entre los sistemas sociales y los sistemas psíquicos autopoiéticos (Luhmann 1984: 210-254). En mi terminología, la operación de la lógica de los sistemas psíquicos (a los que prefiero llamar sistemas socio-individuales) es la dimensión crucial no de las gramáticas de producción de los discursos mediatizados, sino de las gramáticas de reconocimiento en recepción.

Desde su comienzo, alrededor de los ochentas del siglo pasado, el diseño metodológico de la mayoría de los estudios de recepción (inclusive los míos) permitieron comprender sólo pequeños fragmentos de las operaciones de los sistemas socio-individuales $^{6}$. Parecía no haber otro camino para obtener discursos significativos de los actores individuales más que a través de productos mediáticos específicos (material de periódicos, películas, programas de televisión, etc.). Este procedimiento metodológico permitió evaluar en un sentido mucho más preciso los llamados "efectos" de tal o cual discurso mediatizado y fue extremadamente importante en la reorientación del debate acerca del poder de los medios masivos. Las claramente diferentes gramáticas de reconocimiento aplicadas por diferentes sistemas socio-individuales al mismo producto mediatizado, indicaron (1) la especificidad cualitativa de la lógica de la recepción operando en las gramáticas de reconocimiento (contrastadas con las de las gramáticas de producción); (2) la complejidad del polo de reconocimiento en una

\footnotetext{
5 A lo largo del "giro de recepción", el medio que concentró el mayor interés investigativo fue la televisión. Ver, entre otros, Morley (1980, 1986, 1992), Verón (1983, 2001, 2013), Livingstone (1990), Silverstone (1994), Katz y Dayan (1994), Liebes y Curran (1998), Dayan (2000).
} 
sociedad y momento dados; (3) la imposibilidad de deducir ningún "efecto" generalizado estudiando sólamente las características semióticas del discurso mediatizado.

Ha llegado el momendo, quizás, de concentrar nuestros esfuerzos en la comprensión de las reglas que dan forma a las múltiples estrategias activadas por los sistemas socio-individuales para hacer frente a un ambiente crecientemente mediatizado. En otras palabras, debemos encontrar nuevos caminos metodológicos para acceder a los procesos a través de los cuales los sistemas socio-individuales usan fenómenos mediáticos para asegurar su propia auto-organización. Contrario a Luhmann, que habla de la "comunicación" como el concepto central cuando se trata de sistemas y subsistemas sociales, y de la "conciencia" cuando se trata de lo que él llama los "sistemas psíquicos", creo que los procesos semióticos, en uno y otro caso, son isomórficos. La diferencia cualitativa resulta aquí no de la diferencia ontológica entre "comunicación" y "conciencia", sino del simple hecho de que lo social y lo socio-individual son sistemas autopoiéticos diferentes -el socio-individual como sistema orgánico, y los sistemas sociales no. En otras palabras, la diferencia cualitativa entre las lógicas operando en producción y en reconocimiento es el resultado de un factor sistémico, no de uno semiótico. Esto no es ninguna sorpresa: no sería desapropiado, en el nivel de las especies, ver la negociación de los sistemas socio-individuales con los ambientes sociales crecientemente mediatizados como una conversación sin fin del homo sapiens consigo mismo.

\section{BIBLIOGRAFÍA}

DAYAN, Daniel (2000), "Télévision, le presque-public", en Réseaux, 100: 429-456.

Eisenstein, Elizabeth (1979), The Printing Press as an Agent of Change, Cambridge University Press, Cambridge.

- (1983), The Printing Revolution in Early Modern Europe, Cambridge University Press, Cambridge.

- (2011), Divine Art, Infernal Machine, University of Pennsylvania Press, Philadelphia.

Goody, Jack (1968), Literacy in Traditional Societies, Cambridge University Press, Cambridge.

- (1977), The Domestication of the savage Mind, Cambridge University Press, Cambridge 1995.

Goody, Jack, WATT, Ian (1963), "The Consequences of Literacy", en Comparative Studies in Society and History, 5: 304-345.

HAIDLE, Miriam Noël (2009), "How to think a simple spear", en de Beaune, Sophie A., Coolidge, Frederick L. and Wynn, Thomas (eds.), Cognitive Archaeology and Human Evolution, Cambridge University Press, Cambridge.

HJARVARD, Stig (2008), "The Mediatization of Society. A Theory of the Media as Agents of Social and Cultural Change", en Nordicom Review, 29: 105-134.

Katz, Elihu, DaYAn, Daniel (1992), Media Events. The Live Broadcasting of History, Harvard University Press, Cambridge.

KaUfFMAn, Stuart (2000), Investigations, Oxford University Press, Oxford/ New York. LEAKeY, Richard (1994), The Origin of Humankind, Perseus Books Group, New York. LÉvi-Strauss, Claude (1958), Anthropologie structurale, Plon, Paris. 
Liebes, Tamar; Curran, James, eds., (1998), Media, Ritual and Identity, Routledge, London.

Livingstone, Sonia (1990), Making Sense of Television, Routledge, London.

Luhmann, Niklas (1984), Social Systems, Stanford University Press Stanford.

Morley, David (1980), The Nationwide Audience, Routledge, London.

- (1986), Family Television, Comedia/Routledge, London.

- (1992), "La réception des travaux sur la reception. Retour sur le public de Nationwide", en Hermès, Cognition, communication, politique, 11-12, pp. 31- 46.

PeIRcE, Charles Sanders (1894), The Essential Peirce. Selected Philosophical Writings, vol. 2, Indiana University Press, Bloomington and Indianapolis 1998.

PHILIP, Robert (2004), Performing Music in the Age of Recording, Yale University Press, New Haven/ London.

Prigogine, Ilya; Stengers, Isabelle (1984), Order out of Chaos: Man's New Dialogue with Nature, Bantam Books, New York.

SiLVERSTONE, Roger (1994), Television and Everyday Life, Routledge, London.

Thompson, John (1995), The Media and Modernity: the Social Theory of the Media, Stanford University Press, Stanford.

VERÓN, Eliseo (1983), "Il est là, je le voit, il me parle”, en Communications 38, pp. 98120.

- (1987), La sémiosis sociale. Fragments d'une théorie de la discursivité, Presses Universitaires de Vincennes, Paris.

- (1986), Semiosis de lo ideológico y del poder. La mediatización, CBC, Universidad de Buenos Aires, Buenos Aires 1995.

- (1994a), "De l'image sémiologique aux discursivités. Le temps d'une photo", en Hermès, Paris, 13-14: 45-64.

- (1994b) "Mediatización, comunicación política y mutaciones de la democracia", en Semiosfera, 2: 5-36

- (2001), El cuerpo de las imágenes, Grupo Editorial Norma, Bogotá.

- (2004), Fragmentos de un tejido, Gedisa, Barcelona.

- (2013), La semiosis social, 2. Ideas, momentos, interpretantes, Paidós-Planeta, Buenos Aires.

\section{RESUMEN}

Inédita contribución del autor argentino en torno a la mediatización.

Palabras clave: teoría de la mediatización, Eliseo Verón. 